\title{
O MONITORAMENTO DO AMBIENTE EM MEIOS DE HOSPEDAGEM: UM ESTUDO COMPARATIVO NAS REGIÕES DE FLORIANÓPOLIS E BALNEÁRIO CAMBORIÚ ${ }^{1}$
}

\author{
ENVIRONMENTAL SCANNING IN THE HOTEL SECTOR: A \\ COMPARATIVE STUDY IN FLORIANÓPOLIS AND BALNEÁRIO \\ CAMBORIÚ REGION'S
}

Everton Luis Pellizzaro de Lorenzi Cancellier - everton@univali.br

Anete Alberton - anete@ univali.br

Professores do Programa de Pós-Graduação em Administração e Turismo

Universidade do Vale do Itajaí - UNIVALI

\begin{abstract}
RESUMO
Embora mais desenvolvidos no exterior, as pesquisa sobre monitoramento do ambiente ainda são incipientes no Brasil e, apensar dos bravos esforços já iniciados, pouco se tem feito para conhecer o processo de monitoramento ambiental em especial quando se trata de organizações inseridas no setor de viagens e turismo. Esse estudo tem por objetivo analisar as práticas de monitoramento do ambiente em meios de hospedagem da região de Florianópolis comparando os resultados com os dados obtidos em pesquisa semelhante realizada na região de Balneário Camboriú. A pesquisa caracteriza-se por ser do tipo exploratório-descritivo, de corte transversal, do tipo levantamento com envio de questionários auto-administrados. Dentre os principais resultados verificou-se que as empresas das duas regiões apresentaram maiores diferenças na utilização de fontes de informação do que nos aspectos dos ambientes monitorados.
\end{abstract}

Palavras-chave: Monitoramento do ambiente; Meios de hospedagem; Fontes de informação.

\section{INTRODUÇÃO}

A abordagem dos sistemas abertos reorientou o avanço da pesquisa em administração, trazendo atenção para os fatores relacionados ao meio externo às organizações. Até então, os estudos clássicos e de relações humanas, em sua essência, focalizavam o melhor e único modo de organizar as empresas sob quaisquer situações, ignorando variáveis situadas externamente. A compreensão de que as análises estruturais baseadas em sistemas fechados não estavam mais explicando as variações nos resultados e no desenho organizacional foi um forte impulso para direcionar pesquisas que abrangessem variáveis além das linhas limítrofes das organizações, ensejando os estudos acerca do ambiente externo que se propagaram a partir da Teoria Contingencial.

\footnotetext{
${ }^{1}$ Uma versão preliminar deste texto foi publicada nos anais do XXXII Encontro da ANPAD em 2008. A pesquisa para realização do estudo apresentado foi financiada parcialmente pelo Programa de Bolsas de Iniciação Científica da Universidade do Vale do Itajaí - PROBIC/UNIVALI.
} 
O ambiente externo das organizações possui um impacto crucial para o crescimento e sobrevivência das organizações e precisa ser decifrado e interpretado pelos dirigentes. Para dar cabo dessa tarefa, dentre outras ações, as empresas precisam identificar e selecionar as variáveis externas relevantes a serem monitoradas e as respectivas fontes que possam informar sobre elas. Essa atividade de leitura e compreensão do ambiente é chamada de monitoramento ou monitoração ambiental.

$\mathrm{O}$ monitoramento do ambiente permite aos dirigentes formular e conhecer o contexto em que a empresa está inserida. Beal (2000) destaca que uma das principais vantagens de adotar práticas de monitoramento ambiental reside na possibilidade de conhecer oportunidades e ameaças que influem no desempenho e na sobrevivência organizacional, capacitando a empresa a formular estratégias competitivas congruentes com as condições ambientais enfrentadas. Embora mais desenvolvido e abundante no exterior, os estudos sobre o monitoramento do ambiente são escassos no Brasil, especialmente quando se trata de empresas ligadas ao setor de viagens e turismo.

Dentro deste enfoque, a pesquisa teve como objetivo geral analisar as práticas de monitoramento do ambiente externo empreendidas pelos dirigentes de empresas hoteleiras da região de Florianópolis comparando-as com os dados obtidos em pesquisa semelhante realizada na região de Balneário Camboriú por Cancellier, Alberton e Santos (2007). Este estudo investigou as seguintes questões de pesquisa. Para a consecução desse objetivo foram realizados os seguintes objetivos específicos: identificar os tipos de informações monitoradas pelos dirigentes das empresas, identificar as fontes de informações utilizadas pelos dirigentes das empresas e comparar os resultados obtidos neste trabalho com os da amostra de empresas da região de Balneário Camboriú.

Assim, esta pesquisa tem por tema o estudo do monitoramento do ambiente na realidade de empresas hoteleiras. Com isto, pretende-se aumentar o conhecimento sobre as práticas de monitoramento expandindo os resultados para organizações da área de turismo. Dado o caráter descritivo-exploratório do estudo, espera-se poder formular questões mais específicas de pesquisa sobre a gestão estratégica e o monitoramento de meios de hospedagem brasileiros.

\section{AMBIENTE ORGANIZACIONAL}

O ambiente é definido por Duncan (1972) como o conjunto de fatores físicos ou sociais relevantes fora dos limites da organização levados em conta no seu processo de tomada de decisão. Segundo Robbins (1990), esse conceito é amplo demais referindo-se a tudo o mais existente além dos limites da organização e abrange inúmeros aspectos sobre os quais a organização não detém controle, o que demanda um sistema de classificação para se possa lidar com a sua natureza.

Uma das primeiras classificações para o ambiente organizacional está no trabalho pioneiro de William Dill na década de 1950 que propôs a distinção entre o ambiente de tarefa e o ambiente geral, cada um composto por entidades ou objetos identificáveis e externos à empresa. O ambiente de tarefa é mais próximo e específico e contem os elementos e fatores de influência imediata para os objetivos organizacionais, tais como por clientes, fornecedores, competidores e organismos regulatórios. $\mathrm{O}$ ambiente geral possui limites que correspondem a toda a sociedade e que influenciam indiretamente os objetivos das organizações, sendo composto por condições econômicas, sociais, culturais e legislativas gerais das sociedades. Para Bourgeois, (1980) a definição do ambiente geral e tarefa uma empresa em específico depende da forma como o domínio 
da firma é definido e como os decisores escolhem navegá-lo. Assim, o ambiente de tarefa pode incluir a tecnologia em uma empresa de manufatura e os aspectos políticos/regulatórios na indústria bancária. Esta tipologia de Dill (1958) tornou-se bastante difundida e tem sido utilizada em diversas pesquisas na área para estudar o ambiente organizacional (DAFT; SORMUNEN; PARKS, 1988; MOHAN-NEIL, 1995; TEARE, 1997; STRANDHOLM; KUMAR; 2003).

\section{MONITORAMENTO AMBIENTAL}

O monitoramento do ambiente pode ser entendido como a forma pela qual os dirigentes obtêm informações relevantes sobre eventos que ocorrem fora da empresa de maneira a guiar futuros cursos de ação (AGUILAR, 1967). Subramanian, Fernandes e Harper (1993) conceituam monitoramento ambiental como o processo pelo qual uma organização coleta informações do ambiente que serão posteriormente utilizadas no seu processo de administração estratégica.

Para monitorar o ambiente os dirigentes podem aumentar ou diminuir a freqüência de obtenção de informações e selecionar os meios através dos quais pretende obtê-la, gerando duas categorias para o processo de monitoramento: freqüência e modo. A freqüência diz respeito ao número de vezes e a quantidade de informações recebidas do ambiente. Os dirigentes podem receber uma grande ou uma pequena quantidade de informações que podem variar de acordo com o aspecto ambiental em foco, com alguns elementos se destacando em relação a outros. $\mathrm{O}$ modo diz respeito aos meios ou fontes através das quais o dirigente apreende sobre o ambiente e podem ser pessoais, impessoais, externas ou internas à organização. $\mathrm{O}$ acesso às fontes pode variar com algumas sendo mais utilizadas do que outras no processo de monitoramento (DAFT; SORMUNEN; PARKS; 1988).

De maneira geral, as pesquisas em monitoramento do ambiente abordam a freqüência e modo procurando identificar as práticas de busca de informações pelas organizações. Assim, a freqüência de busca de informação do macroambiente e do ambiente de tarefa e as fontes utilizadas para obtê-las predominam nas pesquisas da área. Nessa linha estão os estudos de Smeltzer et al. (1988), Daft, Sormunen e Parks (1988), Fann e Smeltzer (1989), Mohan-Neiil (1995), Analoui e Karami (2002), Strandholm e Kumar (2003) e MacGee e Sawyerr (2003). No Brasil são encontrados os estudos de Fidelis e Cendon (2002), Barbosa (2006) Cancellier, Alberton Silva (2007). (2007). Em menor número, na área de turismo há os estudos de Olsen, Murthy e Teare (1994), Teare (1997), Wu, Costa e Teare (1998) e no Brasil o estudo de Cancellier, Alberton e Santos (2007) cujos achados são detalhados nos resultados para comparação com a amostra obtida na pesquisa desse trabalho.

Smeltzer et al. (19880 identificaram a frequiência de monitoramento das áreas do ambiente e as fontes de informação mais usadas por organizações de pequeno porte. As áreas do ambientes mais monitoradas foram o mercado de atuação e as condições da economia e dentre as fontes predominaram as informais, com destaque para a família do proprietário e contatos pessoais com os clientes, com os competidores não sendo vistos como fonte importante de informação. Os competidores também receberam menor atenção no estudo Fann e Smeltzer (1989), que mostrou que pequenas empresas, independentemente de porte, idade, receita ou setor, não valorizam a concorrência e consideram que se seu produto é bom, ele será vendido pouco interferindo as práticas dos competidores. No entanto, em estudo mais recente na indústria eletro-eletrônica, Analoui e Karami (2002) verificaram que a rivalidade entre os concorrentes e a força 
dos clientes foram as áreas do ambiente de tarefa mais monitoradas enquanto tecnologia e economia no macroambiente foram considerados os aspectos de maior impacto e monitoramento.

Os estudos de Strandholm e Kumar (2003) e Mohan-Neiil (1995) procuraram examinar diferenças no monitoramento entre pequenas e grandes empresas. Ambos os estudos verificaram leve correlação positiva entre as variáveis porte e freqüência de monitoramento do ambiente. Mohan-Neiil (1995), no entanto, agregou a influência da idade ao fator porte e encontrou maiores diferenças no processo de monitoramento entre empresas mais velhas e mais novas do que entre maiores e menores, sugerindo que a idade é uma variável mais significativa do que o porte para as diferenças nas práticas de monitoramento.

O monitoramento tem sido estudado em conjunto com a percepção do ambiente e alguns estudos indicam que há significativa associação entre percepção de incerteza ambiental e padrão de monitoramento do ambiente. Daft, Sormunen e Parks (1988) constataram que o esforço de monitoramento é dirigido para as áreas do ambiente percebidas como mais incertas com clientes, concorrentes e tecnologias sendo mais monitorados. A incerteza percebida também gerou impacto no acesso a fontes uma vez que as empresas responderam ao aumento da incerteza ambiental com maior frequêencia de uso de todos os tipos de fontes de informação, em especial uso mais intenso de fontes pessoais. MacGee e Sawyerr (2003) observaram uma associação positiva significativa entre uso de fontes pessoais e percepção de incerteza ambiental nas áreas de tecnológica e concorrência e constaram que o tempo de vida das empresas influi nessa relação, com empresas de menor idade usando mais fontes do tipo externas e pessoais de informação.

No Brasil, alguns estudos investigaram o processo de monitoramento, identificando a freqüência e modo de monitoramento, bem como relacionando-o com o porte e a idade das organizações. Fidelis e Cendon (2002), em estudo realizado com indústrias do setor metal mecânico mineiro, verificaram que as empresas não procuram informações sobre concorrentes ou o fazem de forma esporádica, constatando a desatenção com os competidores por parte de pequenas e médias empresas brasileiras. No mesmo sentido, Menezes e Almeida (1997) identificaram que informações sobre os concorrentes estão entre as de menor importância para uma amostra de pequenas empresas paranaenses.

Em estudo comparativo sobre o uso de fontes de informação por profissionais de pequenas e grandes empresas de diversos setores, Barbosa (2006) verificou que aqueles que atuam em grandes empresas acessam mais fontes internas tanto do tipo escrita quanto do tipo pessoal e confiam mais em fontes governamentais e documentais internas do que aqueles que atuam em pequenas e médias empresas. Pesquisando a associação do porte e da idade organizacional ao monitoramento do ambiente, Cancellier, Alberton e Silva (2007) verificaram em uma amostra de pequenas e médias empresas de vários setores que tendências de mercado e financiadores são monitoradas com maior freqüência nas empresas maiores e que aspectos ligados aos concorrentes e fornecedores predominam significativamente em empresas mais antigas, sugerindo que ambas as variáveis, porte e idade, influenciam o monitoramento, porém com impactos diversos.

$\mathrm{Na}$ área de viagens e turismo alguns foram realizados e focando o monitoramento em grandes corporações hoteleiras. Olsen, Murthy e Teare (1994), estudando grandes hoteleiras internacionais verificaram que as principais preocupações envolviam a incerteza em relação a clientes e competidores. Teare (1997), em pesquisa com grandes empresas hoteleiras do Reino Unido, constatou associação positiva entre monitoramento 
e desempenho e maior atenção para os impactos do ambiente econômico, de financiamento e para necessidades /expectativas dos clientes. Wu, Costa e Teare (1998) identificaram que os gerentes de unidade de redes multinacionais atuantes no leste europeu e China dedicam mais do seu tempo no monitoramento do ambiente de tarefa do que no macroambiente.

\section{ASPECTOS METODOLÓGICOS}

Esta pesquisa caracteriza-se por ser um estudo exploratório- descritivo do tipo levantamento ou survey com corte transversal. Os estudos descritivos procuram identificar e mensurar categorias e variáveis componentes de um fenômeno investigado. Nessa pesquisa as categorias mais amplas investigadas foram a frequiência de monitoramento do ambiente externo das organizações subdividindo-o em elementos do ambiente de tarefa e do macroambiente. Os estudos exploratórios, para Triviños (1987) permitem aumentar a experiência em torno de problemas de pesquisa e servem para elaborar novas questões que direcionem pesquisas futuras quando o fenômeno é ainda pouco conhecido. O caráter exploratório-descritivo desta pesquisa está embasado nos parcos estudos existentes acerca do monitoramento do ambiente em empresas hoteleiras aliado ao objetivo de identificar práticas de monitoramento do ambiente e utilização de fontes de informação nessas organizações.

A pesquisa do tipo levantamento ou survey para Bryman (1989), procura coletar dados em um número determinado de variáveis e inferir o grau de causalidade ou relação entre elas, obtendo dados geralmente por meio de questionários. O corte transversal é caracterizado pelo fato de se pesquisar fenômeno existente no momento da realização pesquisa, sem investigação da sua evolução no tempo, o que caraterizaria um corte longitudinal.

A população alvo da pesquisa foi composta pelos meios de hospedagem localizados na região de Florianópolis, que incluiu os municípios de São José, Biguaçu e Palhoça. A listagem da população foi obtida mediante fornecimento do cadastro viabilizado pela Secretaria de Turismo da Prefeitura Municipal de Florianópolis SETUR-PMF e pela Secretaria de Estado da Cultura, Turismo e Esporte de Santa Catarina. Nas listagens constava o nome fantasia dos empreendimentos, razão social e endereço. Uma vez condensadas as listagens em uma única procedeu-se o encaminhamento de questionários auto-administráveis após contato prévio via telefone com as empresas. No entanto, parte dos respondentes optou pelo preenchimento do questionário junto ao pesquisador, no momento da vistia ou recolhido do instrumento. Foram obtidos 70 (setenta) questionários em empresas da região de Florianópolis sendo 48 de Florianópolis, 13 de Palhoça, oito de São José e uma de Biguaçu.

O questionário utilizado foi o mesmo aplicado na amostra de meios de hospedagem da região de Balneário Camboriú e aplicado por Cancellier, Alberton e Silva (2007). Um pré-teste com empresas de Florianópolis não acusou mudanças no instrumento.

Para análise dos dados utilizou-se a estatística descritiva com as medidas de média, desvio padrão, contagem de freqüência e cálculos percentuais de forma a identificar os tipos de informações com maior e menor freqüência de monitoramento, as fontes com maior e menor freqüência de utilização e as principais necessidades de obtenção de informações pelas empresas pesquisadas. Para as diferenças entre as amostras, utilizaram-se os testes $t$ e qui quadrado do SPSS versão 13.0. Os resultados da pesquisa foram divididos em duas partes: primeiro são apresentados os dados que caracterizam 
os respondentes e as empresas e, em seguida, são analisados e comparados os dados relativos ao monitoramento das empresas das amostras das duas regiões.

\section{RESULTADOS DA PESQUISA}

Os resultados da pesquisa são apresentados em quatro partes: na primeira descreve-se as características dos respondentes em termos de sexo, idade e ocupação no empreendimento; na segunda, as características das empresas pesquisadas em termos de idade, auto-classificação do negócio, porte e desempenho; na terceira são analisados os dados acerca da freqüência de monitoramento do ambiente e na última são analisados os dados acerca da freqüência de utilização de fontes de informação pelas empresas. Em todas as seções dos resultados os dados obtidos na pesquisa são comparados com aqueles levantados na região de Balneário Camboriú por Cancellier. Alberton e Santos (2007).

\subsection{Caracterização dos respondentes}

Observando os dados da Tabela 1 a seguir constata-se que os respondentes dos 70 hotéis pesquisados da região de Florianópolis em sua maioria são homens, possuem mais de 40 anos de idade e são sócios com atividade no negócio, indicando diferenças em relação ao grupo investigado na região de Balneário Camboriú no que diz respeito à idade e ocupação e semelhanças em relação à distribuição por gênero.

Tabela 1. Características dos respondentes - Região de Florianópolis e de Balneário Camboriú

\begin{tabular}{|c|c|c|c|c|}
\hline \multirow{2}{*}{$\begin{array}{ll} & \text { Característica } \\
\text { Sexo } & \end{array}$} & \multicolumn{2}{|c|}{ Região de Florianópolis } & \multicolumn{2}{|c|}{$\begin{array}{c}\text { Região de Balneário } \\
\text { Camboriú }\end{array}$} \\
\hline & Freq. & $\%$ & Freq. & $\%$ \\
\hline Masculino & 41 & $58,57 \%$ & 27 & $60,00 \%$ \\
\hline Feminino & 29 & $41,43 \%$ & 18 & $40,00 \%$ \\
\hline Idade (anos) & Freq.* & $\%$ & Freq. & $\%$ \\
\hline De 20 (exclusive) até 30 & 12 & $17,39 \%$ & 14 & $31,11 \%$ \\
\hline De 30 (exclusive) até 40 & 14 & $20,29 \%$ & 16 & $35,56 \%$ \\
\hline De 40 (exclusive) até 50 & 15 & $21,74 \%$ & 10 & $22,22 \%$ \\
\hline De 50 (exclusive) até 60 & 20 & $28,98 \%$ & 5 & $11,11 \%$ \\
\hline Acima de 60 & 8 & $11,59 \%$ & 0 & $0,00 \%$ \\
\hline Ocupação & Freq. & $\%$ & Freq. & $\%$ \\
\hline Sócio-proprietário sem atividades no negócio & 0 & $0 \%$ & 1 & $2,22 \%$ \\
\hline Sócio-proprietário com atividades no negócio & 40 & $57,14 \%$ & 17 & $37,78 \%$ \\
\hline Diretor/Gerente não proprietário & 23 & $32,86 \%$ & 23 & $51,11 \%$ \\
\hline Contador não proprietário & 0 & $0,00 \%$ & 2 & $4,44 \%$ \\
\hline Outra & 7 & $10,00 \%$ & 2 & $4,44 \%$ \\
\hline Total & 70 & $100 \%$ & 45 & $100 \%$ \\
\hline
\end{tabular}

Em ambas as regiões houve uma relação de aproximadamente 3 respondentes homens para cada duas mulheres. Embora exista uma proporção maior de mulheres respondentes na amostra da região de Florianópolis o teste qui quadrado não rejeitou a hipótese de independência da variável em relação às regiões $(\alpha=0,879)$, indicando que a distribuição dos respondentes por gênero são equivalentes.

Quanto à idade, se em torno de $61 \%$ dos respondentes da região de Florianópolis possuem mais de 40 anos, em Balneário Camboriú essa faixa etária responde por apenas 
$22 \%$ dos entrevistados. A jovialidade dos respondentes de uma área em relação à outra também pôde ser identificada na diferença entre as médias de idade entre as regiões (45 e 37,5 anos) cujo teste $t$ bi caudal rejeitou a igualdade $(\alpha=0,003)$.

Quanto à ocupação no empreendimento, os respondentes da região de Florianópolis em sua maioria informaram serem sócios com atividades no negócio (57\%), seguidos de dirigentes não proprietários (33\%). Em Balneário Camboriú essas proporções se invertem, com dirigentes não proprietários sendo a maioria seguido de sócios com atividade no negócio, muito embora as duas categorias, em ambas as regiões, somem em torno de $90 \%$ dos respondentes. O predomínio dessas duas categorias explica-se pelo fato do questionário solicitar a opinião dos profissionais responsáveis pela gestão do empreendimento.

O teste qui quadrado da variável confirmou a associação da variável com a região $(\alpha=0,039)$, indicando que predominam sócios com atividades no negócio na região de Florianópolis e dirigentes não proprietários na região de Balneário Camboriú. Isso sugere que na região de Balneário Camboriú é mais freqüente a contratação de profissionais contratados para a gestão do empreendimento no lugar do proprietário uma vez que, na aplicação dos questionários priorizava-se o contato com o dono caso estivesse presente no empreendimento.

\subsection{Caracterização das empresas pesquisadas}

Para a caracterização das empresas foram investigadas as variáveis idade, autoclassificação dos empreendimentos, porte e desempenho.

A amostra dos empreendimentos da região de Florianópolis mostrou uma composição que equilibra empresas mais novas e mais antigas cobrindo várias faixas etárias (Tabela 2). Em torno de 53\% possuíam até 10 anos de idade - média de 13,3 anos - em contraste com as empresas da amostra da região de Balneário Camboriú que se mostraram mais velhas com $69 \%$ possuindo mais de 10 anos de idade - média de 19,6 anos. A diferença de idade entre as amostras também foi verificada no teste $t$ realizado com as médias que resultou em alta significância tanto quando as variâncias são assumidas como iguais $(\alpha=0,009)$ como quando são assumidas como desiguais $(\alpha=0,016)$.

Em relação ao tipo de negócio a maioria dos empreendimentos da região de Florianópolis se classificou como pousadas seguido de hotel de trânsito/dormitório (Tabela 2), enquanto na amostra da região de Balneário Camboriú predominaram hotéis de lazer e hotéis de negócios. Assim como em relação ao porte, as duas amostras apresentaram diferenças significativas na auto-classificação com o teste qui quadrado confirmando a associação das diferenças na variável com a região $(\alpha=0,000)$.

Tabela 2. Idade e Classificação das empresas - Região de Florianópolis e de Balneário Camboriú

\begin{tabular}{|c|c|c|c|c|c|c|c|c|c|}
\hline \multirow[t]{2}{*}{ Idade (anos) } & \multicolumn{2}{|c|}{$\begin{array}{c}\text { Região de } \\
\text { Florianópolis }\end{array}$} & \multicolumn{2}{|c|}{$\begin{array}{c}\text { Região de } \\
\text { Baln. Camb. }\end{array}$} & \multirow[t]{2}{*}{ Auto-classificação } & \multicolumn{2}{|c|}{$\begin{array}{c}\text { Região de } \\
\text { Florianópolis }\end{array}$} & \multicolumn{2}{|c|}{$\begin{array}{c}\text { Região de } \\
\text { Baln. Camb. }\end{array}$} \\
\hline & Freq. & $\%$ & Freq. & $\%$ & & Freq. & $\%$ & Freq. & $\%$ \\
\hline Até 5 & 14 & 20,29 & 6 & 13,33 & Hotel de negócios & 10 & 14,29 & 11 & 25,58 \\
\hline De 5 (excl.) até 10 & 23 & 33,33 & 10 & 22,22 & Hotel de lazer & 7 & 10,00 & 20 & 46,51 \\
\hline De 10 (excl.) até 20 & 20 & 28,99 & 13 & 28,88 & Hotel de trânsito & 13 & 18,57 & 8 & 18,61 \\
\hline De 20 (excl.) até 30 & 7 & 10,14 & 14 & 31,11 & Pousada & 40 & 57,14 & 4 & 9,30 \\
\hline De 30(excl.) até 40 & 2 & 2,90 & 16 & 35,56 & & & & & \\
\hline De 40 (excl.) até 50 & 3 & 4,35 & 10 & 22,22 & & & & & \\
\hline Mais de 50 & 0 & 0,00 & 5 & 11,11 & & & & & \\
\hline Total & 69 & 100 & 45 & 100 & Total & 70 & 100 & 43 & 100 \\
\hline
\end{tabular}

Fonte: dados da pesquisa 
O porte das empresas foi medido pelas variáveis números de leitos e números de empregados e podem ser observados na Tabela 3. Os dados indicam que as empresas das duas regiões diferem em relação ao tamanho, com a região de Florianópolis apresentando empreendimentos de menor porte em que a grande maioria tem menos 100 leitos (média de 55,07) enquanto na região de Balneário Camboriú a maioria possui mais de 100 leitos (média 174,23). Embora em ambas as regiões predominem empresas com menos de 20 empregados, a região de Florianópolis difere-se com média de 6,36 em comparação com a média de 20,87 empregados para a região de Balneário Camboriú. Os testes $t$ de diferença entre médias foram altamente significativos tanto em relação ao número de leitos $(\alpha=0,000)$ quanto em relação ao número de funcionários $(\alpha=0,000)$.

As diferenças de porte permanecem quando se observa a variável receita bruta dos empreendimentos (Tabela 4) com uma concentração de empresas com faturamento anual inferior a R \$ 120 mil na amostra da região de Florianópolis (94\%) enquanto na de Balneário Camboriú prevalecem empresas com faturamento superior a R 120 mil $(59 \%)$.

Tabela 3. Porte das empresas da amostra - Região de Florianópolis e de Balneário Camboriú

\begin{tabular}{|c|c|c|c|c|c|c|c|c|c|}
\hline \multirow[t]{2}{*}{ Número de leitos } & \multicolumn{2}{|c|}{$\begin{array}{c}\text { Região de } \\
\text { Florianópolis }\end{array}$} & \multicolumn{2}{|c|}{$\begin{array}{c}\text { Região de } \\
\text { Baln. Camb. }\end{array}$} & \multirow{2}{*}{$\begin{array}{l}\text { Número de } \\
\text { empregados }\end{array}$} & \multicolumn{2}{|c|}{$\begin{array}{c}\text { Região de } \\
\text { Florianópolis }\end{array}$} & \multicolumn{2}{|c|}{$\begin{array}{c}\text { Região de } \\
\text { Baln. Camb. }\end{array}$} \\
\hline & Freq. & $\%$ & Freq. & $\%$ & & Freq & $\%$ & Freq. & $\%$ \\
\hline Até 100 & 61 & $88,41 \%$ & 14 & $40,00 \%$ & Até 10 & 61 & $87,14 \%$ & 18 & $40,00 \%$ \\
\hline De 100 (excl.) a 200 & 6 & $8,69 \%$ & 8 & $22,86 \%$ & De 10 (excl. ) a 20 & 5 & $7,14 \%$ & 10 & $22,22 \%$ \\
\hline De 200 (excl.) a 300 & 2 & $2,90 \%$ & 9 & $25,71 \%$ & De 20(excl.) a 40 & 2 & $2,86 \%$ & 10 & $22,22 \%$ \\
\hline Mais de 300 & 0 & $0,00 \%$ & 4 & $11,43 \%$ & Mais de 40 & 2 & $2,86 \%$ & 7 & $15,56 \%$ \\
\hline Total & 69 & $100 \%$ & 35 & $100 \%$ & Total & 70 & $100 \%$ & 45 & $100 \%$ \\
\hline
\end{tabular}

Fonte: dados da pesquisa

Para o desempenho foi utilizada a taxa de ocupação dos últimos 12 meses, informada pelos dirigentes dos empreendimentos pesquisados. Nessa variável a amostra da região de Florianópolis indicou valores superiores (média de 70\%) aos da amostra da região de Balneário Camboriú (média de 49,3\%) com o teste $t$ indicando ser a diferença altamente significativa $(\alpha=0,000)$. Uma das explicações para essa diferença pode estar na maior suscetibilidade de Balneário Camboriú a sazonalidade da demanda turística. Embora ambas as regiões sofram com a baixa estação, Florianópolis tem se tornado nos últimos anos um destino para negócios e eventos que podem estar contribuindo para a diminuição dos impactos negativos da baixa estação nos empreendimentos da localidade.

Tabela 4. Desempenho das empresas da amostra - Região de Florianópolis e de Balneário Camboriú

\begin{tabular}{|c|c|c|c|c|c|c|c|c|c|}
\hline \multirow{2}{*}{$\begin{array}{c}\text { Taxa de ocupação } \\
(\%)\end{array}$} & \multicolumn{2}{|c|}{$\begin{array}{c}\text { Região de } \\
\text { Florianópolis }\end{array}$} & \multicolumn{2}{|c|}{$\begin{array}{c}\text { Região de } \\
\text { Baln. Camb. }\end{array}$} & \multirow[t]{2}{*}{ Receita bruta anual (R\$) } & \multicolumn{2}{|c|}{$\begin{array}{c}\text { Região de } \\
\text { Florianópolis }\end{array}$} & \multicolumn{2}{|c|}{$\begin{array}{c}\text { Região de } \\
\text { Baln. Camb. }\end{array}$} \\
\hline & Freq. & $\%$ & Freq. & $\%$ & & Freq. & $\%$ & Freq. & $\%$ \\
\hline Até 40 & 4 & 10,53 & 15 & 37,50 & Até $120 \mathrm{mil}$ & 60 & 86,96 & 19 & 45,23 \\
\hline De 40 (excl.) até 60 & 10 & 26,32 & 20 & 50,00 & De 120,01 até $500 \mathrm{mil}$ & 5 & 7,25 & 7 & 16,67 \\
\hline De 60(excl.) até 80 & 13 & 34,21 & 5 & 12,50 & De 500,01 até 1,2 milhão & 3 & 4,35 & 11 & 26,19 \\
\hline Mais de 80 & 11 & 28,95 & 0 & 0,00 & Mais de 1,2 milhão & 1 & 1,45 & 5 & 11,90 \\
\hline Total & $38 *$ & 100 & 40 & 100 & Total & 69 & 100 & 42 & 100 \\
\hline
\end{tabular}

Enc. Bibli: R. Eletr. Bibliotecon. Ci. Inf., Florianópolis, n. esp., 2ºm. 2008 


\subsection{Monitoramento do Ambiente nas Regiões Pesquisadas}

O monitoramento do ambiente nas empresas pesquisadas das duas regiões foi obtido através da utilização de uma escala que variou de 1 (freqüência muito baixa) a 5 (freqüência muito alta) indicando o grau de freqüência de obtenção de informações para 18 (dezoito) aspectos do ambiente de tarefa e macro. Para o ambiente de tarefa ou operacional foram investigadas variáveis relativas a concorrentes, clientes, fornecedores, tendências de mercado e financiamento; e para o macroambiente foram investigadas variáveis ligadas a economia, tecnologia, demografia, política, cultura e sociedade. A Tabela 5 a seguir apresenta as médias e desvios padrão da freqüência de monitoramento obtida nas duas regiões e os resultados dos testes $t$ de diferença entre as médias.

Tabela 5. Freqüência de monitoramento do ambiente - Região de Florianópolis e de Balneário Camboriú

\begin{tabular}{|c|c|c|c|c|c|c|c|c|}
\hline \multirow{2}{*}{ Aspecto do Ambiente Externo } & \multicolumn{3}{|c|}{$\begin{array}{l}\text { Região de } \\
\text { Florianópolis }\end{array}$} & \multicolumn{3}{|c|}{$\begin{array}{l}\text { Região de Balneário } \\
\text { Camboriú }\end{array}$} & \multirow{2}{*}{ Teste $\mathbf{t}$} & \multirow{2}{*}{ Sig. } \\
\hline & Média & D.P. & $\begin{array}{l}\text { Necess. } \\
\text { Inf.(\%) }\end{array}$ & Média & D.P. & \begin{tabular}{|l|} 
Necess. \\
Inf. $(\%)$
\end{tabular} & & \\
\hline Preços praticados pelos concorrentes (AT) & 2,94 & 1,67 & 52,90 & 3,53 & 1,16 & 37,80 & $-2,08$ & $0,040 *$ \\
\hline $\begin{array}{l}\text { Mudanças nos serviços dos concorrentes } \\
\text { (AT) }\end{array}$ & 2,54 & 1,60 & 51,50 & 2,67 & 1,04 & 64,40 & $-0,46$ & 0,647 \\
\hline $\begin{array}{l}\text { Mudanças no Marketing dos concorrentes } \\
\text { (AT) }\end{array}$ & 2,46 & 1,57 & 48,50 & 2,44 & 0,97 & 60,00 & 0,05 & 0,961 \\
\hline $\begin{array}{l}\text { Introdução de novos produtos pelos } \\
\text { concorrentes (AT) }\end{array}$ & 2,40 & 1,48 & 44,10 & 2,73 & 1,07 & 66,70 & $-1,31$ & 0,194 \\
\hline $\begin{array}{l}\text { Custos e resultados financeiros dos } \\
\text { concorrentes (AT) }\end{array}$ & 1,41 & 0,84 & 33,80 & 1,60 & 0,78 & 51,10 & $-1,19$ & 0,238 \\
\hline Necessidades dos clientes (AT) & 4,83 & 0,51 & 88,20 & 3,87 & 1,12 & 82,20 & 6,26 & $0,000 *$ \\
\hline $\begin{array}{l}\text { Perfil dos clientes (socioeconômico e } \\
\text { distribuição geográfica) (AT) }\end{array}$ & 3,78 & 1,43 & 60,30 & 3,49 & 1,10 & 60,00 & 1,17 & 0,245 \\
\hline $\begin{array}{l}\text { Utilização que os clientes fazem dos } \\
\text { produtos e serviços (AT) }\end{array}$ & 4,71 & 0,66 & 76,50 & 3,27 & 1,16 & 68,90 & 8,53 & $0,000 *$ \\
\hline $\begin{array}{l}\text { Preços e prazos praticados pelos } \\
\text { fornecedores (AT) }\end{array}$ & 3,29 & 1,89 & 69,10 & 3,51 & 1,08 & 51,10 & $-0,73$ & 0,469 \\
\hline $\begin{array}{l}\text { Fornecedores - inovação em } \\
\text { insumos/serviços (AT) }\end{array}$ & 2,61 & 1,82 & 61,80 & 3,27 & 0,94 & 60,00 & $-2,22$ & $0,028 *$ \\
\hline Identificação de novos fornecedores (AT) & 2,39 & 1,73 & 61,80 & 3,29 & 0,94 & 57,80 & $-3,21$ & $0,002 *$ \\
\hline $\begin{array}{l}\text { Mudanças nas tendências do mercado de } \\
\text { atuação (crescimento, declínio, novos } \\
\text { segmentos de clientes, novos usos para o } \\
\text { produto, etc) (AT) }\end{array}$ & 2,47 & 1,55 & 77,90 & 3,58 & 1,08 & 75,60 & $-4,18$ & $0,000^{*}$ \\
\hline Práticas de bancos e financiadores (AT) & 1,55 & 1,09 & 33,80 & 2,89 & 1,25 & 51,10 & $-6,04$ & $0,000 *$ \\
\hline $\begin{array}{l}\text { Surgimento de inovações e tecnologias } \\
\text { aplicadas aos produtos, serviços ou } \\
\text { processos do empreendimento (MA) }\end{array}$ & 2,36 & 1,51 & 76,50 & 3,20 & 1,01 & 73,30 & $-3,29$ & $0,001 *$ \\
\hline $\begin{array}{l}\text { Condições gerais da economia ( EX: taxas de } \\
\text { juros, inflação, câmbio, PIB) (MA) }\end{array}$ & 2,69 & 1,60 & 57,40 & 3,42 & 1,34 & 55,60 & $-2,56$ & $0,012 *$ \\
\hline $\begin{array}{l}\text { Condições sócio-culturais da sociedade } \\
\text { (MA) }\end{array}$ & 3,30 & 1,41 & 82,40 & 3,16 & 1,13 & 68,90 & 0,60 & 0,553 \\
\hline Condições demográficas da população (MA) & 2,62 & 1,60 & 57,40 & 3,04 & 1,10 & 62,20 & $-1,54$ & 0,126 \\
\hline Leis e normas que regulam o setor (Ma) & 3,90 & 1,52 & 75,00 & 3,44 & 1,22 & 73,30 & 1,69 & 0,094 \\
\hline Média geral & 2,90 & & & 3,13 & & & & \\
\hline
\end{tabular}

(AT) Ambiente de Tarefa; (M) Macro Ambiente

* Nível de significância a 5\%

Fonte: dados da pesquisa 
O esforço geral de monitoramento parece ser semelhante entre as regiões, uma vez que as duas médias gerais $(3,13$ e 2,90) que englobam todos os aspectos não apresentaram uma grande diferença $(0,23)$. No entanto, não obstante esse equilíbrio no esforço geral de monitoramento, em metade dos aspectos investigados verificou-se que as médias são diferentes entre as regiões indicando que as diferenças estão na valorização de determinados aspectos do ambiente.

As diferenças parecem estar mais no ambiente de tarefa do que no macroambiente. Dos 13 aspectos ligados ao ambiente de tarefa foram encontradas diferenças de média em sete deles contemplando aspectos ligados a clientes, concorrentes, fornecedores, tendências de mercado e financiamento, enquanto que dos cinco aspectos do macroambiente apenas dois (economia e tecnologia) acusaram diferença entre as médias. A amostra da região de Florianópolis apresentou média superior apenas nos aspectos ligados a clientes - necessidades e uso que fazem dos produtos e serviços, e médias inferiores nos demais aspectos.

Dentre as maiores diferenças (valores próximos ou superiores a 1,00) entre a região de Florianópolis e Balneário Camboriú, estão os aspectos uso dos produtos e serviços pelos clientes $(1,44)$, práticas de bancos e financiadores $(-1,34)$, tendências de mercado ($1,11)$ e necessidades dos clientes $(0,96)$. Algumas possíveis explicações para essas diferenças podem estar no fator sazonalidade que afeta as regiões e no porte das organizações das duas amostras.

Ambas as regiões recebem um grande fluxo de visitantes na temporada de verão, no entanto, a região de Florianópolis parece enfrentar melhor o período de baixa estação. Nos últimos anos, a realização de eventos tem se intensificado e a cidade tem recebido significativo espaço na mídia como destino de destaque e local privilegiado para residir. A melhoria na perspectiva de obter hóspedes na baixa estação pode ter estimulado os empreendimentos locais a investir tempo e atenção para aspectos ligados aos clientes como necessidades e uso que fazem dos produtos/serviços oferecidos. Em contrapartida, para a região de Balneário Camboriú pode haver menor estímulo ao esforço de atenção aos clientes se o fluxo tradicionalmente é abundante no verão e muito árduo na baixa estação, sugerindo que as ações da organização pouco afetam esse ciclo sazonal.

Uma das possíveis explicações para as diferenças nos aspectos práticas de bancos e financiadores e nas tendências de mercado pode estar no porte das empresas. As necessidades captação de recursos e financiamento crescem na medida em que as organizações crescem e aumentam de tamanho. Empresas maiores tendem a apresentar fluxos financeiros mais sofisticados bem como maior capacidade de captar recursos, em parte devido às garantias que pode oferecer. A amostra da região de Balneário Camboriú é formada por empresas notadamente maiores: $39 \%$ faturam anualmente mais de 500 mil reais e sua média de funcionários e de número de leitos é três vezes superior às da região de Florianópolis, que apresenta menos de $6 \%$ da amostra com faturamento anual superior a 500 mil reais.

A Tabela 6 abaixo apresenta os seis aspectos que alcançaram as maiores e as menores médias de freqüência de monitoramento nas duas regiões e contribuem para analisar em que medida as áreas divergem na valorização dos aspectos do ambiente externo. 
Tabela 6 - Aspectos MAIS e MENOS monitorados - Região de Florianópolis e de Balneário Camboriú

\begin{tabular}{|c|c|c|c|c|c|}
\hline \multirow{2}{*}{ Região } & \multirow{2}{*}{\multicolumn{2}{|c|}{ Aspecto do Ambiente Externo }} & \multicolumn{2}{|c|}{ Freqüência } & \multirow{2}{*}{$\begin{array}{l}\text { Necessita mais } \\
\text { informações? } \\
\quad \operatorname{SIM}(\%)\end{array}$} \\
\hline & & & Média & D.P. & \\
\hline \multirow{12}{*}{$\begin{array}{c}\text { Regi } \\
\text { ão } \\
\text { de } \\
\text { Flori } \\
\text { anóp } \\
\text { olis }\end{array}$} & \multirow{6}{*}{$\begin{array}{c}\text { MA } \\
\text { IS } \\
\text { Mo } \\
\text { nito } \\
\text { rad } \\
\text { oS }\end{array}$} & Necessidades dos clientes & $4,83^{*}$ & 0,51 & 88,20 \\
\hline & & Utilização que os clientes fazem dos produtos e serviços & $4,71 *$ & 0,66 & 76,50 \\
\hline & & Leis e normas que regulam o setor & 3,90 & 1,52 & 75,00 \\
\hline & & $\begin{array}{l}\text { Perfil dos clientes (socioeconômico e distribuição } \\
\text { geográfica) }\end{array}$ & 3,78 & 1,43 & 60,30 \\
\hline & & Condições sócio-culturais da sociedade & 3,30 & 1,41 & 82,40 \\
\hline & & Preços e prazos praticados pelos fornecedores & 3,29 & 1,89 & 69,10 \\
\hline & \multirow{6}{*}{$\begin{array}{c}\text { ME } \\
\text { NO } \\
\text { S } \\
\text { Mo } \\
\text { nito } \\
\text { rad } \\
\text { os }\end{array}$} & Custos e resultados financeiros dos concorrentes & 1,41 & 0,84 & 33,80 \\
\hline & & Práticas de bancos e financiadores & $1,55^{*}$ & 1,09 & 33,80 \\
\hline & & $\begin{array}{l}\text { Surgimento de inovações tecnologias aplicadas aos } \\
\text { produtos, serviços ou processos do empreendimento }\end{array}$ & $2,36^{*}$ & 1,51 & 76,50 \\
\hline & & Identificação de novos fornecedores & $2,39 *$ & 1,73 & 61,80 \\
\hline & & Introdução de novos produtos pelos concorrentes & 2,40 & 1,48 & 44,10 \\
\hline & & Mudanças no Marketing dos concorrentes & 2,46 & 1,57 & 48,50 \\
\hline \multirow{12}{*}{$\begin{array}{c}\text { Regi } \\
\text { ão } \\
\text { de } \\
\text { Baln } \\
\text { eári } \\
\text { o } \\
\text { Cam }\end{array}$} & \multirow{6}{*}{$\begin{array}{l}\text { MAIS } \\
\text { Monit } \\
\text { orado } \\
\text { S }\end{array}$} & Necessidades dos clientes & $3,87 *$ & 1,12 & 82,20 \\
\hline & & $\begin{array}{l}\text { Mudança nas tendências do mercado de atuação } \\
\text { (crescimento, declínio, novos segmentos de clientes, } \\
\text { novos usos para o produto, etc) }\end{array}$ & $3,58^{*}$ & 1,08 & 75,60 \\
\hline & & Preços praticados pelos concorrentes & $3,53 *$ & 1,16 & 37,80 \\
\hline & & \begin{tabular}{|l|l|} 
Preços e prazos praticados pelos fornecedores \\
\end{tabular} & 3,51 & 1,08 & 51,10 \\
\hline & & $\begin{array}{l}\text { Perfil dos clientes (socioeconômico, distribuição } \\
\text { geográfica) }\end{array}$ & 3,49 & 1,10 & 60,00 \\
\hline & & Leis e normas que regulam o setor & 3,44 & 1,22 & 73,30 \\
\hline & \multirow{6}{*}{$\begin{array}{c}\text { MEN } \\
\text { OS } \\
\text { Monit } \\
\text { orado } \\
\text { S }\end{array}$} & Custos e resultados financeiros dos concorrentes & 1,60 & 0,78 & 51,10 \\
\hline & & Mudanças no marketing dos concorrentes & 2,44 & 0,97 & 60,00 \\
\hline & & Mudança nos serviços dos concorrentes & 2,67 & 1,04 & 64,40 \\
\hline & & Introdução de novos produtos pelos concorrentes & 2,73 & 1,07 & 66,70 \\
\hline & & Práticas de bancos e financiadores & $2,89 *$ & 1,25 & 51,10 \\
\hline & & Condições demográficas da população & 3,04 & 1,10 & 62,20 \\
\hline
\end{tabular}

* aspectos com médias estatisticamente diferentes entre as regiões

Fonte: dados da pesquisa

$\mathrm{Na}$ amostra da região de Florianópolis dos seis aspectos com maiores médias de monitoramento três estão relacionados com a variável cliente, um com mudanças sócioculturais, um com a variável política-regulação e um com a variável fornecedor. Quando se compara esta lista com os de maior média da região de Balneário Camboriú, verifica-se que há coincidência em três aspectos, divergência nos outros três e que dos oito aspectos diferentes que aparecem conjuntamente nas listas quatro apresentaram diferenças no teste $t$. O aspecto necessidades dos clientes, embora com médias diferentes nas regiões, figura em primeiro lugar nas duas listas, indicando que ambas o valorizam como um dos principais a serem monitorados. Desta forma, pode-se depreender que as divergências em relação aos aspectos mais monitorados nas duas regiões residem nos aspectos tendências de mercado, preços dos concorrentes e uso que os clientes fazem dos produtos/serviços.

Esses dados indicam que a amostra da região de Florianópolis dá maior ênfase à variável cliente do que a da região de Balneário Camboriú, ao mesmo tempo em que, comparativamente, monitora menos os preços dos concorrentes e as tendências de 
mercado. Tal fato pode estar associado à presença de maior número de pousadas, normalmente empreendimentos menores e familiares onde o foco costuma estar mais centrado nos hóspedes e questões operacionais do negócio.

A exceção fica para o aspecto preço dos concorrentes em que a maioria das empresas da região de Balneário Camboriú não indicou a necessidade de mais informações. Esse aspecto, no entanto, é mais simples de ser compreendido e fácil de ser obtido do que as variáveis ligadas aos clientes, que podem demandar inúmeros contatos para se ter uma visão mais adequada do seu conteúdo e natureza.

$\mathrm{O}$ aspecto necessidades dos clientes, embora com médias diferentes nas regiões, figura em primeiro lugar nas duas listas, indicando que ambas o valorizam como um dos principais a serem monitorados. Desta forma, pode-se depreender que as divergências em relação aos aspectos mais monitorados nas duas regiões residem nos aspectos tendências de mercado, preços dos concorrentes e uso que os clientes fazem dos produtos/serviços.

Uma característica comum às amostras é que os aspectos mais monitorados são aqueles em que os empreendimentos indicam haver a necessidade de obter mais informações sobre eles. Necessidade dos clientes, tendências de mercado e uso que os clientes fazem dos produtos, maiores médias nas duas regiões, são aspectos que apresentaram alto percentual de resposta sim à pergunta sobre se há necessidade de obter mais informações. Esse resultado mostra que a maior freqüência de obtenção de informações não é suficiente para proporcionar os dados necessários sobre o aspecto, sugerindo que os processos de monitoramento adotados pelas empresas pesquisadas não têm sido eficientes.

Analisando-se os seis aspectos de menor média de monitoramento (Tabela 6), verificase que na região de Florianópolis três deles estão relacionados com concorrentes e os demais estão relacionados a financiadores, fornecedores e tecnologia. A comparação com aqueles de menor média na região de Balneário Camboriú mostra que há coincidência em quatro aspectos, divergência em outros quatro e que dos oito aspectos diferentes que aparecem conjuntamente nas listas de menos monitorados apenas três apresentam diferenças no teste $t$. Assim, as diferenças ficam por conta das práticas de bancos/financiadores, inovações tecnológicas e identificação de novos fornecedores. Embora o monitoramento em bancos e financiadores figure entre os menos monitorados nas duas regiões é o aspecto que apresenta a segunda maior diferença de média $(-1,34)$ indicando que as regiões realmente divergem nesse quesito.

Um fenômeno que chama a atenção entre as menores médias de monitoramento é a presença de vários aspectos ligados à variável concorrente, três na amostra da região de Florianópolis e quatro na de Balneário Camboriú. Embora o aspecto "Custos e resultados financeiros dos concorrentes" seja reconhecidamente algo difícil de obter, outros aspectos dos concorrentes como mudanças no marketing, mudanças nos serviços e introdução de novos produtos são fatores que, como os preços, podem ser obtidos sem maiores dificuldades e são importantes para as decisões estratégicas das organizações.

Em relação à necessidade de informação, as empresas indicaram uma necessidade menor de obter mais dados sobre os aspectos com menor média de monitoramento do indicaram para os aspectos com maior média de monitoramento. $\mathrm{Na}$ amostra da região de Florianópolis isso fica mais nítido uma vez que o conjunto de aspectos ligados aos concorrentes e a prática de bancos/financiadores foram justamente aqueles em que menos empresas informaram precisar de mais informações. 


\subsection{Uso de Fontes de Informação nas Regiões Pesquisadas}

O uso de fontes de informação pelas empresas pesquisadas foi obtido através da utilização de uma escala que variou de 1 (se a empresa não obtém informações por esta fonte) a 5 (se a empresa sempre obtém informações por esta fonte) indicando o grau de freqüência de contato para uma lista de 19 fontes que incluiu as do tipo pessoais, impessoais, externas e internas à organização. A Tabela 7 apresenta as médias e desvio padrão da frequiência de acesso às fontes obtidas nas duas regiões e os resultados dos testes $t$ de diferença entre as médias.

Tabela 7. Fontes de Informação - Região de Florianópolis e de Balneário Camboriú

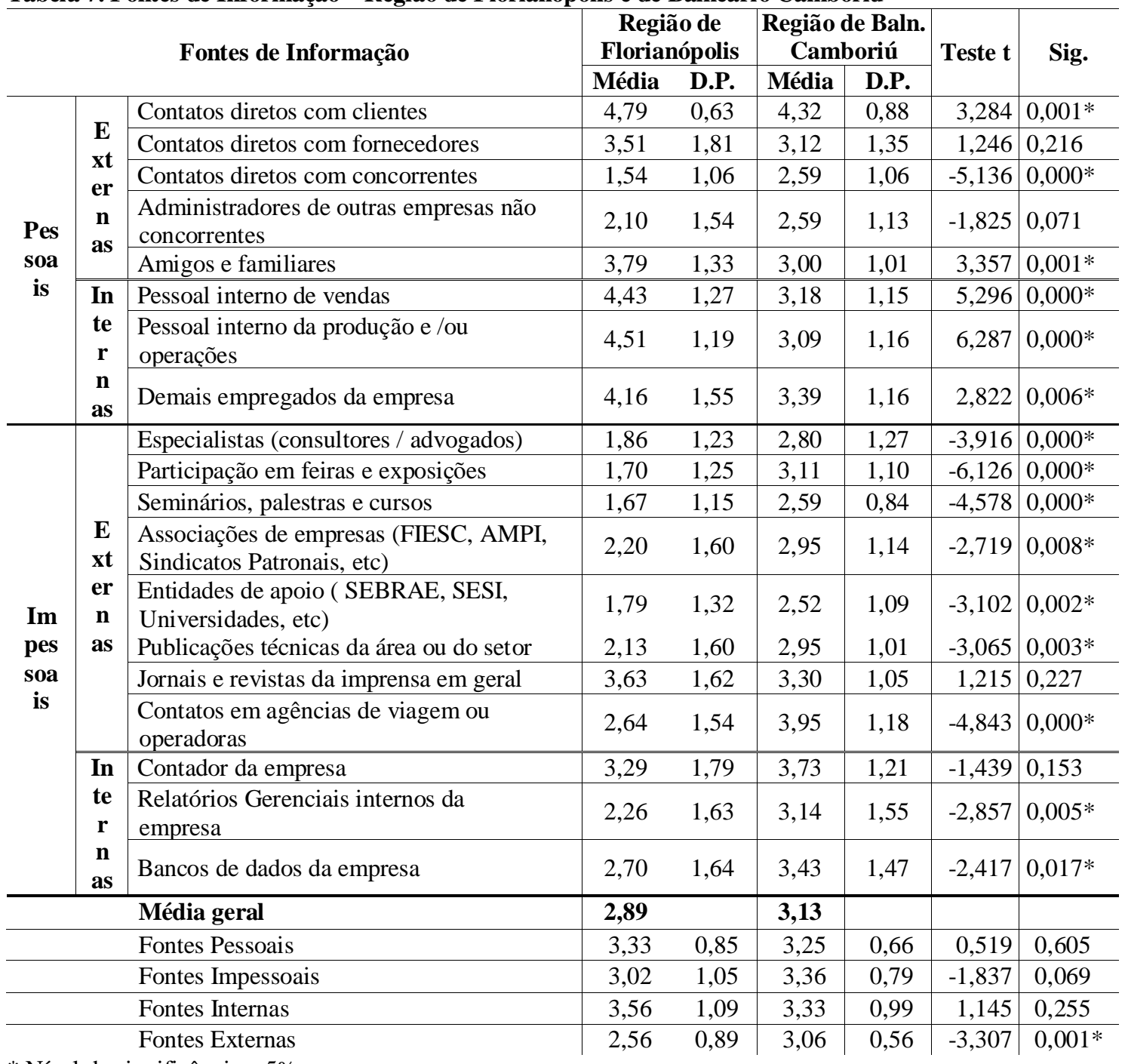

* Nível de significância a 5\%

Fonte: dados da pesquisa

O padrão de frequiência de acesso às fontes de informação guarda semelhança com o observado na freqüência de monitoramento do ambiente: as duas médias gerais $(3,13 \mathrm{e}$ 2,89 ) tendem a se aproximar e as diferenças significativas são encontradas quando se observa cada fonte individualmente. No entanto, essas diferenças foram em maior número, das 19 fontes investigadas o teste $t$ acusou significância ao nível de 0,05 em 15 
delas, envolvendo todos os tipos de fontes, sejam pessoais, impessoais, externas ou internas à organização. Apenas contatos com fornecedores, contatos com administradores de empresas não concorrentes, jornais e revistas da imprensa em geral e contatos com o contador da empresa não indicaram diferenças de média no teste $t$. $\mathrm{O}$ agrupamento das fontes mostrou que apenas as fontes do tipo externas mostraram médias diferentes entre as regiões, com a amostra da região de Florianópolis fazendo menor freqüência de utilização, o que reforça o direcionamento da análise para as fontes individualmente.

As maiores diferenças entre a amostra da região de Florianópolis e a de Balneário Camboriú foram encontradas nas seguintes fontes: contatos com pessoal interno de produção/operações $(1,42)$, participação em feiras/exposições $(-1,41)$, contatos em agências de viagens/operadoras $(-1,31)$, contatos com pessoal interno de vendas $(1,25)$, contatos diretos com concorrentes $(-1,05)$, contatos com especialistas/consultores/advogados $(-0,94)$ e participação em seminários/palestras/cursos $(-0,92)$.

A amostra da região de Florianópolis apresentou médias estatisticamente superiores a de Balneário Camboriú para as fontes contatos com pessoal interno de produção/operações $(1,42)$, pessoal interno de vendas $(1,25)$, amigos e familiares $(0,79)$, demais empregados da empresa $(0,77)$ e contatos diretos com clientes $(0,47)$; e médias inferiores para as fontes participação em feiras e exposições $(-1,41)$, contatos em agências de viagens/operadoras $(-1,31)$, contatos diretos com concorrentes $(-1,05)$, contatos com consultores/advogados (-0,94), participação em seminários/palestras/cursos (-0,92), relatórios gerenciais internos $(-0,88)$, publicações técnicas da área $(-0,82)$, associações de empresa $(0,75)$ e entidades de apoio $(-0,73)$. Esses dados mostram que todas as médias em que a amostra da região de Florianópolis foi superior envolvem fontes pessoais (três internas e uma externa à empresa), enquanto as em a região de Balneário Camboriú foi superior envolvem fontes do tipo impessoais ( 7 externas e 1 interna) e pessoais (uma externa). Esses dados mostram que a amostra da região de Florianópolis apresentou médias bastante superiores para duas fontes do tipo pessoais e internas e médias inferiores para fontes externas e impessoais.

Uma explicação para a maior freqüência de uso de fontes pessoais e internas na amostra da região de Florianópolis pode estar no predomínio de empreendimentos menores do tipo pousadas. Nessas, o dono ou dirigente mantém atividades de gestão e próximas das operações do negócio o que torna mais constantes os contatos pessoais com clientes e funcionários. Também costumam ser negócios que envolvem o trabalho de membros da família, o que explicaria o maior contato com a fonte amigos e familiares.

A Tabela 8 abaixo apresenta as cinco fontes que alcançaram as maiores e as menores médias de freqüência de utilização nas duas regiões e permite analisar em que medida as áreas divergem em termos de valorização e uso das fontes. 
Tabela 8. Fontes MAIS e MENOS monitoradas - Região de Florianópolis e de Balneário Camboriú

\begin{tabular}{|c|c|c|c|c|}
\hline \multirow{2}{*}{ Região } & \multirow{2}{*}{\multicolumn{2}{|c|}{ Fontes de Informação }} & \multicolumn{2}{|c|}{ Freqüiência } \\
\hline & & & Média & D.P. \\
\hline \multirow{10}{*}{$\begin{array}{c}\text { Região } \\
\text { de } \\
\text { Florian } \\
\text { ópolis }\end{array}$} & \multirow{5}{*}{$\begin{array}{c}\text { MAIS } \\
\text { Monito } \\
\text { radas }\end{array}$} & Contatos diretos com clientes & $4,79 *$ & 0,63 \\
\hline & & Pessoal interno da produção e /ou operações & $4,51 *$ & 1,19 \\
\hline & & Pessoal interno de vendas & $4,43 *$ & 1,27 \\
\hline & & Demais empregados da empresa & $4,16^{*}$ & 1,55 \\
\hline & & Amigos e familiares & $3,79 *$ & 1,33 \\
\hline & \multirow{5}{*}{$\begin{array}{c}\text { MENO } \\
\mathbf{S} \\
\text { Monito } \\
\text { radas }\end{array}$} & Contatos diretos com dirigentes/ empregados dos concorrentes & $1,54 *$ & 1,06 \\
\hline & & Seminários, palestras e cursos & $1,67 *$ & 1,15 \\
\hline & & Participação em feiras e exposições & $1,70^{*}$ & 1,25 \\
\hline & & Entidades de apoio ( SEBRAE, SESI, Universidades, etc) & $1,79 *$ & 1,32 \\
\hline & & Especialistas (consultores / advogados) & $1,86^{*}$ & 1,23 \\
\hline \multirow{10}{*}{$\begin{array}{c}\text { Região } \\
\text { de } \\
\text { Balneá } \\
\text { rio } \\
\text { Cambo } \\
\text { riú }\end{array}$} & \multirow{5}{*}{$\begin{array}{c}\text { MAIS } \\
\text { Monito } \\
\text { radas }\end{array}$} & Contatos diretos com os clientes & $4,32 *$ & 0,88 \\
\hline & & Demais empregados da empresa & $3,95^{*}$ & 1,16 \\
\hline & & Contador da empresa & 3,73 & 1,21 \\
\hline & & Bancos de dados da empresa & $3,43 *$ & 1,47 \\
\hline & & Contatos em agências de viagem ou operadoras & $3,39 *$ & 1,18 \\
\hline & \multirow{5}{*}{$\begin{array}{c}\text { MENO } \\
\mathrm{S} \\
\text { Monito } \\
\text { radas }\end{array}$} & Entidades de apoio (SEBRAE, SESI, Universidades, etc) & $2,52 *$ & 1,09 \\
\hline & & Administradores de outras empresas não concorrentes & 2,59 & 1,13 \\
\hline & & Contatos diretos com dirigentes/ empregados dos concorrentes & $2,59 *$ & 1,06 \\
\hline & & Seminários, palestras e cursos & $2,59 *$ & 0,84 \\
\hline & & Especialistas (consultores /advogados) & $2,80^{*}$ & 1,27 \\
\hline
\end{tabular}

* aspectos com médias estatisticamente diferentes entre as regiões

Fonte: dados da pesquisa

$\mathrm{Na}$ amostra da região de Florianópolis das cinco fontes com maiores médias de utilização três estão relacionadas aos contatos com funcionários da empresa, uma com clientes e uma com amigos/familiares. Quando se comparam esses dados com as de maior média da região de Balneário Camboriú, verifica-se que há coincidência em dois aspectos, divergência em três e que dos oito aspectos que aparecem conjuntamente nas listas sete apresentaram diferenças no teste $t$.

Entre as fontes mais utilizadas para obtenção de informações destaca-se que o contato com clientes foi a mais utilizada em ambas as regiões e que demais empregados da empresa também figura entre as fontes mais utilizadas em ambas as áreas, embora as médias entre as regiões tenham sido diferentes no teste $t$. As divergências residem no uso das fontes pessoal interno de operações, pessoal interno de vendas e contatos com amigos/familiares que indicam uma valorização de fontes pessoais próximas ao gestor na amostra da região de Florianópolis e nas fontes "bancos de dados da empresa" e "contatos em agências de viagem ou operadoras" que indicam uma valorização de fontes impessoais pelos gestores na amostra da região de Balneário Camboriú.

Dentre as fontes com menor média de frequiência de uso, as duas regiões apresentam listas semelhantes. Embora os testes $t$ indiquem médias diferentes, as fontes entidades de apoio, contatos diretos com os concorrentes, seminários, palestras e cursos e especialistas figuram como as fontes menos monitoradas nas duas regiões. A única divergência fica por conta de participação em férias e exposições na amostra da região de Florianópolis, uma vez que administradores de empresas não concorrentes, presente 
apenas na amostra da região de Balneário Camboriú não indicou diferença de média no teste $t$.

\section{CONCLUSÕES}

As duas regiões comparadas nesse estudo têm suas economias com marcante presença de atividades turísticas, que exercem um papel fundamental na geração de empregos e renda para a comunidade local e da região. A pesquisa constatou que o monitoramento das informações do ambiente externo é presente nas amostras de empresas de meios de hospedagem das duas regiões e em ambas algumas informações e fontes são privilegiadas enquanto outras recebem menor atenção.

Os aspectos ligados aos clientes são permanentemente monitorados enquanto os que dizem respeito aos concorrentes figuram entre os menos monitorados, excetuando-se os preços praticados pelos concorrentes. A análise desses resultados mostra que as empresas pesquisadas buscam poucas informações sobre os concorrentes sugerindo que nesta região os empreendimentos hoteleiros costumam negligenciar este tipo de informação. Em relação às fontes, verificou-se que as empresas das duas regiões privilegiam os contatos diretos com clientes como fonte de informação.

Dentre as diferenças encontradas, as relativas a freqüência de uso de fontes foram em maior número do as relativas a freqüência de monitoramento do ambiente. Os dados, em conjunto, apontam para uma maior concentração do monitoramento na região de Florianópolis - foco no cliente - e indicam que a amostra de Balneário Camboriú distribui o esforço em um conjunto maior de variáveis ambientais. Da mesma forma, na região de Florianópolis privilegia-se o uso de fontes pessoais enquanto a de Balneário Camboriú faz uso freqüente de fontes pessoais e documentais, internas e externas à organização.

Essas diferenças ganham relevância uma vez que as regiões indicam manter esforços semelhantes de monitoramento, com médias aproximadas, e a amostra é relativamente pequena. Amostras menores demandam diferenças maiores para que o teste $t$ acuse significância.

Como recomendações para estudos futuros sugerem-se que a amostra dos hotéis seja ampliada para outras localidades permitindo uma comparação mais ampla entre as empresas hoteleiras brasileiras. O detalhamento do uso de fontes para cada tipo de informação do ambiente e as possíveis barreiras que os empreendimentos hoteleiros brasileiros enfrentam na atividade de monitoramento também se mostram temas promissores. Cabe destacar que as empresas de hospedagem podem apresentar diferenças nas práticas de monitoramento conforme sua idade e porte, e descobrir em que medida essas diferenças existem seria uma contribuição para o conhecimento na área e recomendação para estudos futuros.

\section{REFERÊNCIAS}

AGUILAR, F. J. Scanning the business environment. New York: The Macmillan Company, 1967.

ANALOUI, F.; KARAMI, A. How chief executives' perception of the environment impacts on company performance. The Journal of Management Development, v. 21, n. 4, 2002.

BARBOSA, R. R. Uso de fontes de informação para a inteligência competitiva: um estudo da influência do porte das empresas sobre o comportamento informacional. Encontros Bibli, n. Especial, 2006. 
BOURGEOIS, L. J. Strategy and environment: a conceptual integration. Academy of Management Review, v. 5, n. 1, 1980.

BRYMAN, A. Research methods and organizational studies. London: Routledge, 1989, 283p.

BEAL, R. M. Competing effectively: Environmental scanning, competitive strategy, and organizational performance in small manufacturing firms. Journal of Small Business Management, v. 38, n. 1, 2000.

CANCELliER, E. L. P. L.; ALBERTON, A.; SANTOS, L. D. R. Monitoramento de informações estratégicas em pequenas empresas: um estudo em hotéis de pequeno porte do Vale do Itajaí-SC. Análise, v. 18, n. 2, 2007.

CANCELliER, E. L. P. L.; ALBERTON, A.; SILVA, A. B. Diferenças na Atividade de Monitoramento de Informações do Ambiente Externo em Pequenas e Médias Empresas: a Influência do Porte e da Idade. IN: ENCONTRO DA ANPAD, 26, 2007, Rio de Janeiro. Anais... Rio de Janeiro, 2007, CD.

DAFT, R. L.; SORMUNEN, J.; PARKS, D. Chief Executive Scanning, Enviromental Characteristics, and Company Performance: and empirical study. Strategic Management Journal, v. 9, n.2, 1988.

DILL, W. R. Environment as an influence on managerial autonomy. Administrative Science Quarterly, v. 20, n. 4, 1958.

DUNCAN, R. B. Characteristics of organization environments and perceived environmental uncertainty. Administrative Science Quarterly, v. 17, n. 3, 1972.

FANN, G. L.; SMELTZER, L. R. The Use Of Information From And About Competitors In Small Business Management. Entrepreneurship Theory and Practice; v. 13, n. 4, Summer 1989.

FIDELIS, J; R. F.; CENDON, B. V. Inteligência empresarial no setor metal mecânico (2002). In: WORKSHOP BRASILEIRO DE INTELIGÊNCIA COMPETITIVA E GESTÃo DO CONHECIMENTO, 3, 2002, São Paulo/SP, Anais... São Paulo: 2002, 1 CD.

McGEE, J. E.; SAWYERR, O. O. Uncertainty and information search activities: a study of owner-managers of small high-technology manufacturing firms. Journal of Small Business Management, v. 41, n. 4, 2003.

MOHAN-NEIL, S. I. The influence of firm's age and size on its environmental scanning activities. Journal of Small Business Management, v. 33, n. 4, 1995.

OLSEN, M. D.; MURTHY, B.; TEARE, R. CEOs perspectives on scanning the global hotel business environment. International Journal of Contemporary Hospitality Management, v. 6(4), 1994.

ROBBINS, S. P. Organization theory, structure, design and applications. 3. ed. New Jersey: Prentice-Hall, 1990.

SMELTZER, L. R.; FANN, G. L.; NIKOLAISEN, V. N. Environmental Scanning Practices in Small Business. Journal of Small Business Management, v. 26, n. 3, Jul. 1988.

STRANDHOLM, K.; KUMAR, K. Differences in environmentla scanning activities between large and small organizations: the advantage of size. Journal of American Academy of Business, v. 3, n. 1/2, 2003.

SUBRAMANIAN, R.; FERNANDES, N.; HARPER, E. Environmental scanning in U.S. companies: their nature and their relationship to performance. Management International Review; v. 33, n. 3, 1993.

TEARE, R. Assessing information needs and external change. International Journal of Contemporary Hospitality Management, v. 9, n. 7, 1997. 
TRIVIÑOS, A. N. S. Introdução à pesquisa em ciências sociais. São Paulo: Atlas, 1987.

WU, A.; COSTA, J.; TEARE, R. Using environmental scanning for business expansion into China and Earsten Europe: the case of transnational hotel companies. International Journal of Contemporary Hospitality Management, v. 10, n. 7, 1998.

\begin{abstract}
Altough most developed abroad, environmental scanning research is still imature in Brazil, in spite off the brave efforts already donne. This study aims to examine the environmental scanning practices in hotels of Florianópolis region comparing the results with data from a similar research conducted in Balneário Camboriú region. Of a exploratory and descriptive nature the study used self-administered questionnaires. Among the main results it was found more differences in the use of information sources than the scanning of environmental sectors.
\end{abstract}

Key words: Environmental scanning; Hotels; Information sources; External environment

Originais recebidos em: 30/09/2008

Texto aprovado em: 06/11/2008 